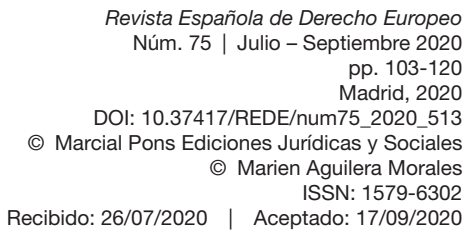

\title{
EL PENÚlTiMO CAPÍTULO SOBRE CLÁUSULAS ABUSIVAS: REFLEXIONES AL HILO DE LA SENTENCIA TJUE IBERCAJA BANCO
}

\author{
THE PENULTIMATE CHAPTER ABOUT UNFAIR TERMS: \\ THOUGHTS RELATED TO THE ECJ RULING IN IBERCAJA BANCO
}

\author{
Marien Aguilera Morales*
}

RESUMEN: La reciente Sentencia TJUE de 9 de julio de 2020 suma importantes novedades a la doctrina del TJUE en materia de cláusulas abusivas en contratos celebrados con los consumidores. En esta ocasión las novedades conciernen a la cláusula de renuncia al ejercicio de acciones por el consumidor, que se considera puede ser abusiva en el marco de las controversias actuales con el profesional, y que siempre es abusiva en el marco de las controversias futuras.

PALABRAS CLAVE: Directiva 93/13/CEE; protección de consumidores; cláusulas abusivas; renuncia al ejercicio de la acción.

ABSTRACT: The recent ECJ ruling of July 9, 2020, adds important news to the ECJ doctrine regarding unfair terms in contracts concluded with consumers. On this occasion, the news concern the clause are related to the resignation to the exercise of actions by the consumer, which is considered to be abusive in the context of

" Profesora Titular de Derecho Procesal de la Universidad Complutense de Madrid y miembro del Instituto de Derecho Europeo e Integración Regional (IDEIR). Correoe: eaguiler@ucm.es. ORCID ID: 0000-0002-8380-1473.

El trabajo se enmarca en el Proyecto de Investigación "Hacia una justicia civil eficiente: desafíos actuales y próximos desde la perspectiva europea" financiado por el Ministerio de Ciencia e Innovación (ref. PID2019-103909GB-100). 
current disputes with the professional, and which is always abusive in the context of future disputes.

KEYWORDS: Council Directive 93/13/EEC; consumer protection; unfair terms; waiver of the right to bring an action.

SUMARIO: INTRODUCCIÓN.-1. EL CONTEXTO: 1.1. El contexto mediato: los "acuerdos novatorios" de las cláusulas suelo. 1.2. El contexto inmediato: 1.2.1. La base fáctica de Ibercaja Banco. 1.2.2. Las cuestiones del Juzgado de Primera Instancia e Instrucción n. ${ }^{\circ} 3$ de Teruel.-2. LAS APORTACIONES DE IBERCAJA BANCO A LA DOCTRINA DE LAS CLÁUSULAS ABUSIVAS: 2.1. Con carácter previo: la renuncia del consumidor al régimen de protección de la Directiva 93/13: 2.1.1. El lienzo de tonos grises. 2.1.2. La luz. 2.2. La posible validez de la cláusula de renuncia de acciones: 2.2.1. Cláusula no negociada individualmente. 2.2.2. Consentimiento libre e informado. 2.2.3. Control de transparencia.-3. LA IMPOSIBLE VALIDEZ DE LA CLÁUSULA DE RENUNCIA DE ACCIONES.-CONCLUSIÓN.-FUENTES CITADAS.

\section{INTRODUCCIÓN}

Como es conocido, la crisis económica e inmobiliaria de 2008 trajo consigo la proliferación de ciertas prácticas bancarias y estas, a su vez, pérdidas multimillonarias para las propias entidades crediticias.

En esto último — también es de general conocimiento- el Derecho de la Unión ha tenido mucho que ver. Aunque, acercando la lupa, lo propio es decir que lo crucial en las pérdidas ha estado en la doctrina gestada por el TJUE al amparo de la Directiva 93/13/CEE, del Consejo, de 5 de abril de 1993, sobre las cláusulas abusivas en los contratos celebrados con los consumidores.

En las próximas páginas se analiza, justamente, uno de los últimos capítulos de esta doctrina: la Sentencia TJUE Ibercaja Banco (2020). Aderezarán el análisis unas reflexiones personales sobre el que sin duda es un nuevo revés de Luxemburgo. Un revés para la banca, sí, pero también para el Tribunal Supremo y para el conjunto mismo de la Administración de Justicia. A la sazón, Ibercaja Banco no solo desautoriza al primero, sino que augura para la segunda nuevas demandas que vendrán a sumarse al caudaloso torrente que la era pos-COVID supondrá para el orden civil de nuestra jurisdicción ${ }^{1}$.

1 Tras Ibercaja Banco (2020), ha recaído la muy importante STJUE Caixabank y $B B V A$ (2020). En ella, el Tribunal de Luxemburgo vuelve a contradecir al Tribunal Supremo, esta vez en lo relativo a la devolución al consumidor de los gastos de constitución y cancelación de la hipoteca, y en la interpretación mantenida por él sobre la "cláusula de comisión de apertura" de los préstamos hipotecarios. Además, pone en el punto de mira del principio europeo de efectividad dos disposiciones nacionales: el art. 1964.1 CC y el art. 394 LEC. 


\section{EL CONTEXTO}

\subsection{El contexto mediato: los "acuerdos novatorios" de las cláusulas suelo}

Ibercaja Banco (2020) guarda relación mediata con las cláusulas suelo o, mejor, con la conocida "sentencia de las cláusulas suelo". Aludo, claro está, a la STS 241/2013; una resolución entre cuyas "bondades" estuvo la de permitir el reembolso de los pagos hechos por los consumidores a sus respectivos bancos en virtud de las cláusulas suelo, pero solo - y esta es la "bondad" a la que irónicamente me refería - a partir del 9 de mayo de 2013.

Fue, en efecto, a raíz de conocerse la Sentencia STS 241/2013 cuando algunas entidades financieras comenzaron a ofertar a sus clientes bien una rebaja en la variabilidad del tipo de interés asociado a sus respectivos préstamos hipotecarios -i.e., una rebaja en la cláusula suelo-, bien la sustitución de estas últimas cláusulas por el tipo de referencia (normalmente el euríbor) y el correspondiente diferencial. Plasmadas en un documento ya redactado y presentado a los prestatarios bajo la denominación "novación modificativa del préstamo", estas o similares ofertas se condicionaban a que los consumidores renunciaran a ejercitar cualquier acción que trajera causa de la formalización y clausulado del contrato de préstamo; la condición, obviamente, incluía la reclamación de los importes abonados hasta ese momento en virtud de la cláusula suelo.

Por lo demás, importa no perder de vista la decena larga de prejudiciales que, en materia de consumo, siguen pendientes de la respuesta del TJUE:

Entre estas cuestiones las hay que interpelan al TJUE sobre aspectos ya resueltos, como la compatibilidad con el Derecho de la Unión de los pactos trabados entre el banco predisponente y el consumidor sobre una posible cláusula nula (Ibercaja SA/ TJ y UK, C-13/19); y, C-268/19); el reparto de los gastos asociados a la concesión de préstamos hipotecarios y el criterio de imposición de costas (YV/ BBVA SA, C-452/19; BX/BBVA SA, C-455/19; JK y KG/Bankia, C-482/19; ED/BBVA SA, C-523/19; HG e IH/ Bankia SA, C-527/19; y $L L, M K / B B V A S A$, C-732/19); o la relativa a si el reembolso de los gastos insertos en un contrato de préstamo hipotecario puede tenerse por un efecto ope legis de la nulidad de la cláusula de gastos o, por el contrario, por una acción autónoma sujeta a plazo de prescripción (Bankia SA y SL, C-31/20).

Las hay también novedosas, como la que sugiere que el deber de control de oficio de las cláusulas abusivas en el marco de la ejecución hipotecaria se extiende más allá de la realización de la garantía y del efecto traslativo de la propiedad (MA/Ibercaja Banco SA, C-600/19); o como la que a finales del año pasado planteaba la Sala Primera del TS sobre la posible oposición de los principios de justicia rogada, congruencia y prohibición de reformatio in peius a los dictados de la Directiva 93/13 (Banco de Caja de España de Inversiones, C-869/19).

Y las hay que aún no se han formulado formalmente, como las que prevén plantearse en relación con la conocida cláusula IRPH: un asunto ya resuelto en Gómez del Moral Guasch/Bankia (2020), pero sobre el que nuestros Juzgados y Audiencias siguen sin ponerse de acuerdo. 
Ni que decir tiene que el grueso de los consumidores se avino a aceptar las nuevas estipulaciones, en principio mucho más ventajosas para ellos que las originales cláusulas suelo.

La avenencia, sin embargo, cambió de signo con Gutiérrez Naranjo y otros (2016). Y es que, en tanto esta Sentencia consideró contraria al Derecho de la Unión aquella decisión de la Sala Primera de limitar temporalmente los efectos restitutorios anudados a la declaración de nulidad de la cláusula suelo, fueron muchos los consumidores que se animaron a demandar a sus respectivos bancos, invocando la nulidad de los acuerdos novatorios trabados con estos y, a partir de ahí, la declaración de nulidad de las cláusulas suelo iniciales y los consabidos efectos restitutorios.

En general estas demandas tuvieron buena acogida en nuestros tribunales. Tanto fue así que, en un primer momento, también la Sala Primera se abonó a la tesis de que los acuerdos novatorios eran nulos e ineficaces (STS $558 / 2017)^{2}$. Al poco, sin embargo, la opinión de la Sala fue otra.

El cambio de opinión vino de la mano de la STS 205/2018 y del argumento consistente en que los acuerdos novatorios no eran propiamente novaciones sino transacciones. Sobre esta premisa la Sala Primera entendió que, ante una situación de incertidumbre sobre la validez de las cláusulas suelo como la generada por la STS 241/2013, resultaba lícito que consumidores y entidades financieras transasen (arts. 1809 y ss. CC). Y resultaba lícito, en su opinión, porque la transacción, amén de no estar expresamente prohibida en materia de consumo y proyectarse sobre una materia disponible, contaba con el aval adicional que tanto el Derecho de la Unión como nuestro Derecho interno proporcionan a la solución extrajudicial de los conflictos en este ámbito $^{3}$. Esto con todo, la Sala hacía hincapié en que, por el modo predispuesto en que se había ofertado y aceptado el acuerdo transaccional, resultaba preciso comprobar ad casum si aquel cumplía el deber de transparencia, pues solo superando este control podría concluirse — como se concluyó en el caso— ${ }^{4}$ que la transacción era válida y eficaz.

2 En apretada síntesis en esta resolución se consideró que la consecuencia anudada a la falta de transparencia material de la inicial cláusula suelo era la nulidad; nulidad que, al ser de pleno derecho y sobre la base del art. 1208 CC, "arrastraba" a la novación posterior.

3 Los avales citados eran, concretamente, la Directiva 2013/11/CEE sobre resolución alternativa de litigios en materia de consumo; y el Real Decreto Ley 1/2017, de 20 de enero, de medidas urgentes de protección de consumidores en materia de cláusulas suelo.

4 Discutiblemente, interpolo. En este sentido hago notar que la conclusión de la Sala Primera se fundó en la consideración de que el control de transparencia material debía entenderse superado con base en el impacto mediático de la STS 241/2013, así como en la circunstancia de que los consumidores habían manifestado de su puño y letra ser conscientes y entender la reducción del suelo ofertada por la entidad financiera. Pretirió, sin embargo, la circunstancia de que la entidad financiera no hubiera proporcionado a los prestatarios información concreta y precisa sobre la carga jurí- 
Pero la decisión de la Sala Primera no fue unánime. Antes bien, uno de sus magistrados formuló voto discrepante con el criterio de la mayoría, en la consideración de que la naturaleza jurídica de aquellos acuerdos no podía ser la propia de la transacción. Por dos razones: de un lado, porque ello implicaba dejar sin efecto las normas imperativas de protección de los consumidores a través de una previa renuncia de acciones legalmente proscrita (art. 10 TRLGDCU, en relación con el art. 86.7 del mismo cuerpo legal); y, de otro lado, porque la renuncia de acciones vulneraba a su entender el derecho a la tutela judicial efectiva e impedía el control de oficio de las cláusulas predispuestas.

Fue así como se avivó la polémica sobre si los consabidos acuerdos novatorios merecían, en lo sustantivo, la consideración de novaciones o transacciones válidas (Muñoz García, 2018a y 2018b). Y fue así como la discusión se extendió a lo procesal. Al fin y al cabo, aquel voto particular presentaba un nuevo nudo gordiano alrededor de aquellos acuerdos: el de la validez $-\mathrm{O}$ no- de la cláusula de renuncia.

Disconformes con el tratamiento dispensado a estas cuestiones desde la Plaza de la Villa de París, varios tribunales se aprestaron a buscar respuestas de su gusto en Luxemburgo. Fue el caso del Juzgado de Primera Instancia n. ${ }^{\circ} 3$ bis de Albacete $^{5}$; de la Sección 5. ${ }^{a}$ de la Audiencia Provincial de Zarago$\mathrm{za}^{6}$; y del Juzgado de Primera Instancia n. ${ }^{\circ} 9$ de Orense ${ }^{7}$.

El primero, no obstante, en dirigirse al TJUE fue el Juzgado de Primera Instancia e Instrucción n. ${ }^{\circ} 3$ de Teruel. A su iniciativa, precisamente, responde Ibercaja Banco.

\subsection{El contexto inmediato}

\subsubsection{La base fáctica de Ibercaja Banco}

Los hechos que estuvieron en la base de las cuestiones prejudiciales turolenses son fiel ejemplo de la práctica bancaria a la que líneas arriba me refería.

$X Z$ adquirió una finca de un promotor inmobiliario, subrogándose en el préstamo hipotecario concedido a este por la entidad de crédito Caja de Ahorros de la Inmaculada de Aragón (luego, Ibercaja Banco). Este inicial contrato contenía una cláusula relativa al tipo de interés máximo y mínimo aplicable al préstamo hipotecario; el primero -el interés máximo o "techo"- se fijó

dica y económica que suponía tanto la cláusula suelo "rebajada" como la cláusula de renuncia de acciones.

5 Este asunto acabó archivándose por desistimiento de la parte demandante en el litigio principal (Globalcaja, 2019),

${ }^{6}$ Cfr. Ibercaja $S A / T J$ y $U K$, ya citado.

7 Cfr. UP/Banco Pastor, ya citado. 
en el 9,75 por 100 anual; el segundo —el interés mínimo o “suelo", en el 3,25 por 100 .

El 4 de marzo de 2014 - recaída, por tanto, la STS 241/2013 - el contrato de préstamo fue modificado en virtud de un "contrato de novación modificativa". Este otro contrato estipulaba una rebaja del suelo inicial, que quedó fijado en el 2,35 por 100. Acompañaba a esta estipulación una declaración manuscrita y firmada por $X Z$ en la que este manifestaba conocer y entender que el interés de su préstamo nunca bajaría de aquel porcentaje. El contrato de novación incorporaba además una cláusula del siguiente tenor: "Las partes ratifican la validez y vigor del préstamo, consideran adecuadas sus condiciones y, en consecuencia, renuncian expresa y mutuamente a ejercitar cualquier acción frente a la otra que traiga causa de su formalización y clausulado, así como por las liquidaciones y pagos realizados hasta la fecha, cuya corrección reconocen”.

El 14 de enero de 2016, XZ reembolsó la última cuota del préstamo hipotecario. No obstante, al año siguiente — recaída, por tanto, la STJUE de 21 de diciembre de 2016-, XZ demandó a Ibercaja, solicitando la declaración de nulidad de la cláusula suelo estipulada originalmente, así como la condena a devolver las cantidades abonadas con arreglo a dicha cláusula.

A la demanda, turnada al Juzgado de Primera Instancia e Instrucción n. 3 de Teruel, se opuso Ibercaja, esgrimiendo que el contrato de novación modificativa del préstamo europeo había subsanado la eventual nulidad de la cláusula suelo. Para $X Z$, por el contrario, este argumento no era correcto, pues en el carácter no vinculante que el art. 6.1 de la Directiva 93/13 confiere a las cláusulas abusivas debía hacerse extensivo a la novación, lo que a la postre implicaba que, al igual que la cláusula suelo, el contrato de novación también era nulo ${ }^{8}$.

\subsubsection{Las cuestiones del Juzgado de Primera Instancia e Instrucción $n .^{\circ} 3$ de Teruel}

Planteada la controversia en los términos vistos, el Juzgado aragonés suspendió el proceso para interpelar al TJUE sobre los siguientes extremos:

8 Recuérdese que, según el apdo. 1 del art. 6 de la Directiva, "no vincularán al consumidor, en las condiciones estipuladas en sus derechos nacionales, las cláusulas abusivas que figuren en un contrato celebrado entre este y un profesional". Y también que, en virtud de esta disposición, la interpretación del TJUE es la de que, en principio, los Jueces están obligados a deducir todas las consecuencias que, según el Derecho nacional, se deriven de la apreciación del carácter abusivo de la cláusula, a fin de que esta no vincule a los consumidores, lo que, en el caso de la cláusula suelo, se traduce en dejar esta última sin aplicación y restituir los importes pagados en virtud de la misma al consumidor. 
1. $\left.{ }^{2}\right)$ Eficacia extensiva del efecto no vinculante ex artículo 6 de la Directiva 93/13. En esto el Juzgado remitente se hizo eco del argumento de XZ. En concreto la duda que trasladó al TJUE fue si el principio de la no vinculación de las cláusulas nulas ex art. 6 Directiva 93/13 se extendía a los contratos o negocios jurídicos posteriores sobre esas cláusulas y, por lo mismo, si estos contratos o negocios debían considerarse también inexistentes e ineficaces.

2. $\left.{ }^{a}\right)$ Aplicación de los controles de transparencia y abusividad a los documentos modificativos o transaccionales del original contrato de préstamo. Focalizada en los documentos que modifican o transigen cláusulas no negociadas, la duda en este punto era si estos documentos - los acuerdos novatorios-participaban de la naturaleza propia de las condiciones generales de la contratación y, por lo mismo, si debía operarse sobre ellos el control de transparencia y/o de contenido.

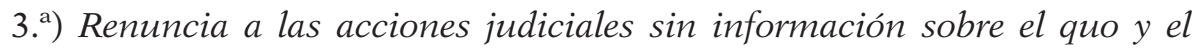
quantum de la cláusula eventualmente abusiva. Esta cuestión puede tenerse por concreción de la anterior en lo relativo a la cláusula de renuncia al ejercicio de acciones. A la sazón, lo que se planteaba era si la firma de una estipulación de renuncia al ejercicio de acciones es también nula cuando los prestatarios no son informados por sus bancos del posible carácter abusivo de la original cláusula suelo, ni del importe que tienen derecho a percibir en virtud de tal tipo de cláusulas.

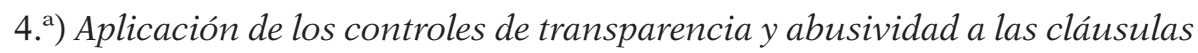
suelo rebajadas. También esta cuestión puede tenerse como concreción de la formulada en segundo lugar solo que aplicada a la cláusula suelo rebajada. Así, en efecto, la duda era si la nueva estipulación tenía que cumplir los controles previstos en los arts. 3.1 y 4.2 de la Directiva 93/13 o, lo que es igual, si la entidad financiera tenía que haber informado al cliente de la carga económica y jurídica que para este último suponía la nueva cláusula suelo.

5. ${ }^{\text {) }) ~ E v e n t u a l ~ c a r a ́ c t e r ~ a b u s i v o ~ d e ~ l a ~ c l a ́ u s u l a ~ d e ~ r e n u n c i a ~ a l ~ e j e r c i c i o ~ d e ~ a c-~}$ ciones. La última cuestión afectaba nuevamente a la cláusula de renuncia de acciones, esta vez para sugerir su abusividad intrínseca [art. 3.1 Directiva 93/13 y anexo (letra q)] en tanto limitativa del derecho de los consumidores al ejercicio de los derechos que pueden nacer o revelarse después de la firma del contrato, como ocurrió con la posibilidad de reclamar la devolución íntegra de los intereses pagados al amparo de Gutiérrez Naranjo y otros.

\section{LAS APORTACIONES DE IBERCAJA BANCO A LA DOCTRINA DE LAS CLÁUSULAS ABUSIVAS}

Pasadas por filtro de la novedad, las respuestas del TJUE a las prejudiciales formuladas por el Juzgado de Teruel tienen por común referencia la renuncia 
del consumidor o, de otra forma, las cuestiones referidas en el apartado anterior bajo los ordinales $1 .^{\mathrm{a}}, 2 .^{\mathrm{a}}, 3 .^{\mathrm{a}}$ y $5 .^{\mathrm{a} 9}$.

Apreciadas en su globalidad, aquellas respuestas pueden resumirse en estas dos:

1. a) La cláusula predispuesta en virtud de la cual el consumidor renuncia a los derechos reconocidos en la Directiva 93/13 en relación con una controversia actual puede ser válida.

2. $\left.{ }^{a}\right)$ La cláusula predispuesta en virtud de la cual el consumidor renuncia a los derechos reconocidos en la Directiva 93/13 en relación con cualquier controversia futura no es válida.

Así expresada, es claro que la solución que el TJUE proporciona al problema de la cláusula de renuncia difiere según el carácter actual o futuro de la controversia que enfrenta al consumidor con el profesional. Veamos por qué.

\subsection{Con carácter previo: la renuncia del consumidor al régimen de protección de la Directiva 93/13}

La respuesta del TJUE a la primera cuestión del Juzgado de Primera Instancia e Instrucción de Teruel fue la que sigue:

El artículo 6, apartado 1, de la Directiva 93/13/CEE del Consejo, de 5 de abril de 1993, sobre las cláusulas abusivas en los contratos celebrados con consumidores, debe interpretarse en el sentido de que no se opone a que una cláusula de un contrato celebrado entre un profesional y un consumidor, cuyo carácter abusivo puede ser declarado judicialmente, pueda ser objeto de un contrato de novación entre ese profesional y ese consumidor, mediante el cual este último renuncia a

9 Sobre la cuestión prejudicial $4 .^{\text {a }}$-relativa a la nueva cláusula suelo (novada/ transigida) - la respuesta de Luxemburgo poco, apenas nada, tiene de novedoso. El TJUE se limita a reiterar su doctrina sobre la exigencia de transparencia aplicable a este tipo de cláusulas, poniendo el acento en que, entre la información que debe suministrar el profesional al consumidor, a fin de que este último se encuentre en condiciones de comprender las consecuencias que para él se derivan de la cláusula suelo, es pertinente incluir la evolución pasada del índice en el que se basa el cálculo del tipo aplicable (apdo. 53).

Lo llamativo es que, con ocasión de esta cuestión, el TJUE se pronuncia también sobre la exigencia de transparencia en relación con la cláusula de renuncia (cuestión prejudicial $3 .^{a}$ ). Y lo hace para negar que, entre la información procurada al consumidor por la entidad crediticia con ocasión del acuerdo novatorio, deban incluirse los concretos importes a los que se renuncia (esto es, la diferencia resultante entre las cantidades abonadas por el consumidor en virtud de la original cláusula suelo y las que debería haber abonado en ausencia de esta cláusula). El argumento que sostiene la negativa es que "en principio, esas cantidades pueden calcularse fácilmente por un consumidor medio normalmente informado y razonablemente perspicaz, siempre que el profesional —en este caso, la entidad bancaria, que reúne los conocimientos técnicos y la información necesarios a este respecto- haya puesto a su disposición todos los datos necesarios" (apdo. 55). 
los efectos que pudieran derivarse de la declaración del carácter abusivo de esa cláusula, siempre que la renuncia proceda de un consentimiento libre e informado por parte del consumidor, extremo este que corresponde comprobar al juez nacional (apdos. 30 y 78.1).

Comparadas estas palabras con las precedentes interrogativas, cabría pensar que Ibercaja Banco incurre en lo que, en terminología procesal, se conoce como incongruencia extra petitum. No en vano por lo que se preguntaba al TJUE era por la extensión del principio de no vinculación a los contratos de novación o transacción sobre una cláusula eventualmente abusiva, no por la facultad del consumidor de renunciar a la protección que la Directiva 93/13 le dispensa.

Personalmente, sin embargo, ningún vicio de incongruencia aprecio en Ibercaja. Antes bien, a mi modo de ver, estamos simple y llanamente ante uno de los muchos casos en que el TJUE reformula las cuestiones prejudiciales que se le plantean, en aras a facilitar una respuesta útil al litigio (SSTJUE Smith, 2017; y Caixabank y BBVA, 2020).

Sea como fuere, lo que es inopinable es que Ibercaja Banco aporta luz a un lienzo hasta ahora presidido por tonalidades grises. El lienzo, naturalmente, es el de la renuncia del consumidor a los derechos reconocidos en la Directiva 93/13.

\subsubsection{El lienzo de tonos grises}

La renuncia del consumidor al régimen de protección de la Directiva 93/13 es asunto sobre el que ya antes se había pronunciado el TJUE.

La primera vez que lo hizo fue en Pannon GSM (2009), y en los siguientes términos: "El Juez nacional no tiene, en virtud de la Directiva, el deber de excluir la aplicación de la cláusula [...] si el consumidor, tras haber sido informado al respecto por dicho Juez, manifiesta su intención de no invocar el carácter abusivo y no vinculante de tal cláusula”. Es más: según también esta resolución, "el derecho a una protección efectiva del consumidor comprende la facultad de renunciar a hacer valer sus derechos, de forma que el juez nacional debe tener en cuenta, en su caso, la voluntad manifestada por el consumidor cuando, consciente del carácter no vinculante de una cláusula abusiva manifiesta, sin embargo, que es contrario a que se excluya, otorgando así un consentimiento libre e informado a dicha cláusula”.

Con similares e incluso idénticas palabras se expresaron más tarde Banif Pluss (2013); Sales Sinués y Drame Bra (2016); Abanca Corporación Bancaria y Bankia (2019) y Dziubak (2019) ${ }^{10}$.

10 Todas las Sentencias mencionadas en texto son objeto de cita expresa en Ibercaja Banco, con la paradójica salvedad de Pannon. El silencio alcanza también a Bankia (2019). 
Este cuerpo de doctrina -importa subrayarlo- se acuñó en el marco de asuntos en que el control judicial de la cláusula ya se había producido y había arrojado un resultado negativo sobre su validez. Más claramente: en las Sentencias previas a Ibercaja Banco (2020), el TJUE no había abordado el tema de la renuncia del consumidor en términos generales, sino en el concreto contexto del deber que incumbe al Juez de extraer todas las consecuencias de una cláusula cuyo carácter abusivo ya había sido apreciado.

Lo anterior da explicación a que hubiera quien negara que lo relativo a la renuncia del consumidor fuese un "acto aclarado". En efecto, a decir de algunas voces, los pronunciamientos del TJUE sobre este asunto no debían interpretarse en el sentido de entender que el régimen europeo de protección al consumidor era renunciable en todo caso (Pazos Castro, 2017; Moreno García, 2019; Achón Bruñén, 2019; y Aguilera Morales, 2019 y 2020). Menos aún, teniendo a la vista lo que algún otro instrumento europeo disponía sobre el particular ${ }^{11}$.

\subsubsection{La luz}

Ibercaja Banco (2020) - ya se ha avanzado- disipa las dudas. A su tenor el consumidor no solo tiene la facultad de renunciar a que el juez deduzca los efectos de una cláusula cuyo carácter abusivo ya ha sido apreciado, sino que también goza de esa facultad en un momento anterior, cuando el carácter abusivo de la cláusula es solo un futurible, una mera posibilidad.

En línea con la propuesta del AG, Ibercaja Banco (2020) niega, por tanto, carácter obligatorio al sistema de protección diseñado por la Directiva 93/13 frente a la utilización de cláusulas abusivas por los profesionales. $\mathrm{O}$ en positivo: admite que, en el marco de una controversia entre un profesional y un consumidor, este último renuncie a hacer valer el potencial carácter abusivo de una cláusula como la suelo, con tal —eso sí- de que su renuncia sea fruto de un consentimiento libre e informado; extremo este cuyo control incumbe al juez nacional.

Previo a este, no obstante, debe procederse a otro control y verificar que el contrato o cláusula que lleva implícita la renuncia del consumidor no ha sido objeto de negociación individual con el profesional. A la sazón, solo en este último caso es aplicable la Directiva 93/13. Por el contrario, si el contrato o cláusula de renuncia ha sido objeto de negociación individual, la Directiva

11 Concretamente, i) el art. 25 de la Dir. 2011/83: "Si la legislación aplicable al contrato es la de un Estado miembro, el consumidor no podrá renunciar a los derechos que le confieran las disposiciones nacionales de transposición de la presente Directiva"; y ii) el art. 41 de la Directiva 2014/17: "Los Estados velarán porque: a) el consumidor no pueda renunciar a los derechos que se le confieren en virtud del Derecho nacional que transpone la presente Directiva". 
93/13 no entra en juego y la validez de la renuncia queda supeditada a su adecuación al Derecho contractual nacional.

\subsection{La posible validez de la cláusula de renuncia de acciones}

\subsubsection{Cláusula no negociada individualmente}

Que la cláusula de renuncia no haya sido objeto de negociación individual con el consumidor tiene, desde la perspectiva europea, más de exigencia general que de presupuesto específico. Al cabo -insistiré en ello una vez más-, la Directiva 93/13 circunscribe su ámbito de aplicación a tal clase de cláusulas. Las cláusulas negociadas, en cambio, se rigen por las normas nacionales que disciplinan los contratos.

Llegados este punto abro un paréntesis para recordar que, conforme a nuestra normativa patria, la renuncia es el objeto característico de la transacción: un contrato caracterizado por las recíprocas concesiones hechas entre las partes con la finalidad de evitar o poner fin a una controversia ya surgida entre ellas (arts. 1809 y ss. CC). Así las cosas, ningún obstáculo legal hay en que, surgida la controversia entre consumidor y profesional, estos lleguen a un acuerdo que implique la renuncia de aquel a ejercitar las acciones que le competen frente a este. Antes al contrario, alcanzar un acuerdo en este sentido es derivación directa de la autonomía de la voluntad y de la libertad contractual; atalayas ambas desde las que es posible proporcionar seguridad jurídica a cualquier situación incierta y litigiosa, como la que hasta hace bien poco rodeaba en nuestro país a las cláusulas suelo ${ }^{12}$.

Hecho el recordatorio y volviendo a las cláusulas no negociadas, es de notar que, conforme a la Directiva 93/13, los criterios que permiten incluir la cláusula de renuncia entre las de este género son dos y cumulativos: ha de tratarse, de un lado, de una cláusula redactada de antemano por el profesional; y, descartarse, de otro, que el consumidor haya influido en su contenido.

Como apunta igualmente la Directiva 93/13, estos criterios se dan "en particular en los contratos de adhesión" (art. 3.2). En otros términos: las cláusulas no negociadas son, por lo general, cláusulas tipo; condiciones generales empleadas sistemáticamente por el profesional en sus relaciones comerciales con una pluralidad de consumidores. Se explica así que el legislador europeo haya elevado el binomio cláusulas no negociadas/cláusulas tipo a la categoría de presunción iuris tantum o, desde otra perspectiva, que haya hecho recaer sobre el profesional la carga de probar el carácter negociado de una cláusula tipo.

12 Repárese en que el art. 21.3 de la Ley 5/2019 prohíbe la incorporación de esta cláusula en las operaciones con tipo de interés variable. La prohibición, no obstante, no afecta a los contratos preexistentes a la entrada en vigor de esta Ley, esto es, a los de fecha anterior al 16 de junio de 2019 (DT 1. ${ }^{\mathrm{a}}$ y DF 16. ${ }^{\mathrm{a}}$ ). 
Sentado lo anterior y descendiendo a lo particular, no hay duda de que, en la mayoría de los casos, los consabidos acuerdos novatorios participan del régimen de las condiciones generales de la contratación. Y no hay duda porque, como se vio, la política bancaria que siguió a la STS 241/2013 fue la de presentar a la generalidad de los clientes que tenían suscrito un préstamo hipotecario con cláusula suelo unas nuevas cláusulas — la de rebaja de la cláusula suelo y la de renuncia de acciones - previamente redactadas y sin posibilidad alguna para los consumidores de influir efectivamente en su contenido.

Lo anterior con todo, algún caso pudo escapar de la mayoría. Algún caso pudo darse en que las nuevas cláusulas contractuales fueran fruto de una previa negociación con el consumidor. De aquí que la directriz de Ibercaja Banco (2020) sea la de que el Juez nacional examine si, en el caso concreto, el consumidor pudo influir en el contenido de las cláusulas litigiosas, teniendo a la vista el conjunto de las circunstancias en las que tales cláusulas le fueron presentadas. En este punto, no obstante, el TJUE se permite añadir algunas consideraciones de cosecha propia; significadamente, la de que el manuscrito del consumidor afirmando comprender el mecanismo de la cláusula suelo no permite concluir por sí solo que la rebaja de la cláusula suelo fue negociada individualmente. Excuso decir que la afirmación vale también para la cláusula de renuncia.

\subsubsection{Consentimiento libre e informado}

Según se deslizó supra, el criterio del TJUE en Ibercaja Banco (2000) es que, para que la renuncia del consumidor sea válida y eficaz, debe ser fruto de un consentimiento libre e informado.

Cuándo debe tenerse por libre el consentimiento es sin embargo cuestión a la que Ibercaja Banco no desciende, quizá — como apunta el AG (Conclusiones en Ibercaja Banco, 2020)_ porque son las normas nacionales en materia de vicios del consentimiento las que dan respuesta al interrogante.

Obviamente son también las normas nacionales las llamadas a despejar la cuestión de si se está o no ante un consentimiento informado. Este, sin embargo, es particular sobre el que el Ibercaja Banco sí se pronuncia: el consentimiento del consumidor es informado — viene a decir-cuando en el momento de formular su renuncia el consumidor es consciente del posible carácter abusivo de la cláusula sobre la que aquella se proyecta y conocedor de las consecuencias jurídicas y económicas que tal renuncia acarrea para él.

\subsubsection{Control de transparencia}

Dicho está que el carácter no negociado de la cláusula de renuncia provoca que esta caiga de lleno en el ámbito de aplicación de la Directiva 93/13 y en el de sus exigencias. Lo que aún no ha sido dicho es que, para el TJUE, esta 
cláusula es de las que integran el "objeto principal" del contrato en el sentido del art. 4, apdo. 2, y el art. 5, de aquella Directiva ${ }^{13}$.

En esto el TJUE coincide con nuestro Tribunal Supremo: en tanto referida al "objeto principal" del contrato, la cláusula de renuncia — como la propia cláusula suelo, la de intereses remuneratorios o la multidivisa- supedita su validez a la superación del control judicial de transparencia; al control de transparencia formal y al control de transparencia material ${ }^{14}$.

Para que la cláusula de renuncia sea válida es necesario, en otras palabras, que haya sido redactada de manera "clara y comprensible" en el sentido y con la extensión que a esta expresión otorga el TJUE. No basta, por tanto, con que resulte comprensible para el consumidor desde el punto de vista gramatical o lingüístico. Es preciso, además, que profesional proporcione un "plus" de información al consumidor, a fin de que este pueda conocer la carga jurídica y económica que aquella cláusula supone para él y decida conscientemente si queda vinculado por ella. De lo contrario, esto es, si el consumidor carece de información suficiente para evaluar las eventuales consecuencias que pueden derivarse de su renuncia, esta debe tenerse por nula e ineficaz (art. 6, aptdo. 1, Dir. 93/13).

A poco que se repare, salta a la vista que este control de transparencia es instrumental respecto del consentimiento libre e informado al que desde Luxemburgo se supedita la validez de la renuncia. En efecto, si aquel control se supera es porque, a la vista de las circunstancias del caso en concreto, es posible concluir que el consumidor aceptó libremente renunciar a las acciones que le concernían frente al profesional en virtud de la (antigua) cláusula suelo, y dispuso, además, de información suficiente para comprender las consecuencias de tal renuncia. Y a la inversa.

La que no está tan clara es la solución que, en este sentido y para el caso concreto, proporciona Ibercaja Banco (2020). De hecho, mientras su funda-

13 Traigo a la vista, para comodidad del lector, la literalidad de sendos preceptos, destacando de ambas lo que aquí interesa: "La apreciación del carácter abusivo de las cláusulas no se referirá - art. 4, apdo. dos-a la definición del objeto principal del contrato ni a la adecuación entre precio y retribución, por una parte, ni a los servicios o bienes que hayan de proporcionarse como contrapartida, por otra, siempre que dichas cláusulas se redacten de manera clara y comprensible".

"En los casos de contratos en que todas las cláusulas propuestas al consumidor o algunas de ellas consten por escrito - art. 5-, estas cláusulas deberán estar redactadas siempre de forma clara y comprensible".

${ }^{14}$ La coincidencia - preciso- se contrae a la idea de someter a control de transparencia la cláusula de renuncia en el marco de los acuerdos novatorios de las cláusulas suelo. La precisión viene a cuento porque, en aquellos otros casos en que la cláusula se inserta en el marco de la contratación de instrumentos financieros complejos, el Tribunal Supremo somete aquella no al filtro de transparencia, sino al control de contenido o abusividad. Ejemplos de ello son la STS 63/2016, respecto de un contrato de permuta financiera (swap); y la STS 137/2019, respecto de una operación de canje obligatorio de obligaciones subordinadas por bonos convertibles en acciones. 
mentación parece ir en una dirección (la validez), su fallo sugiere marchar en la dirección contraria (la nulidad) ${ }^{15}$.

Oscuridades a un margen, lo importante es que, abstracción hecha del caso concreto, Ibercaja (2020) no opone reparos insalvables a la renuncia del consumidor, si de lo que se trata es de aportar seguridad jurídica a su relación contractual con el prestamista o, lo que es lo mismo, de solventar una controversia actual sobre la validez de una cláusula, como en el caso fue la cláusula suelo. El haz.

\section{LA IMPOSIBLE VALIDEZ DE LA CLÁUSULA DE RENUNCIA DE ACCIONES}

La oposición del TJUE a la renuncia del consumidor es empero radical, insuperable, cuando esta tiene por objeto el ejercicio de acciones judiciales en lo referente a controversias futuras. Entonces la cláusula de renuncia es —sin el "puede"—abusiva. El envés.

En este punto recurro de nuevo al paréntesis para incidir sobre un extremo al que hasta ahora no he tenido oportunidad de referirme: el eje normativo que sirve a la interpretación del TJUE en todo lo relativo a la cláusula de renuncia al ejercicio de acciones del consumidor es el art. 3, apdo. 1, de la Directiva 93/13 y su anexo.

Las cláusulas contractuales — dispone el primero- que no se hayan negociado individualmente se considerarán abusivas si, pese a las exigencias de la buena fe, causan en detrimento del consumidor un desequilibrio importante entre los derechos y obligaciones de las partes que se derivan del contrato".

El anexo, por su parte, contiene un listado indicativo de cláusulas que pueden ser consideradas abusivas, entre las que se incluyen aquellas que tienen por objeto o efecto "suprimir u obstaculizar el ejercicio de las acciones judiciales o recursos por parte del consumidor (punto 1 , literal q) ${ }^{16}$.

15 Nótese que, aun cuando el control de transparencia es de la incumbencia exclusiva del juez nacional, el TJUE es competente para deducir de las disposiciones de la Directiva 93/13 los criterios que el juez nacional puede o debe aplicar al efectuar tal control (Verein für Konsumenteninformation, 2016). En Ibercaja Banco, qué duda cabe, el TJUE hace uso de esta competencia. A la sazón, en ella se alude a determinadas circunstancias - destacadamente, la incertidumbre sobre el carácter abusivo de la cláusula suelo original y el dato de que el acuerdo novatorio se firmase tras la STS 241/2013 (apdos. 72 y 74) — que apuntan a que, en el caso concreto, el consentimiento del consumidor fue libre e informado y, por lo mismo, que su renuncia fue válida. El modo, no obstante, en que está redactado su fallo, da que pensar lo contrario, esto es, que el TJUE se decanta por la nulidad de la cláusula [apdo. 78. 4), párrafo segundo]; y otro tanto es lo que se infiere - aquí claramente y sin lugar a dudas-de las Conclusiones del AG (puntos 80 a 84).

${ }^{16}$ Hago hincapié en que se trata de un listado indicativo y no exhaustivo (art. 3, apdo. 3, de la Directiva 93/13), lo que se traduce en que las cláusulas contenidas en 
Pues bien, bajo el común tamiz de estas disposiciones lo que Ibercaja Banco (2020) defiende es que la renuncia a ejercitar acciones judiciales en relación con la antigua cláusula suelo y la renuncia mutua a ejercitar acciones judiciales en relación con la nueva cláusula suelo merecen un tratamiento diferente: la primera puede ser calificada como "abusiva" cuando, en particular, el consumidor no haya podido disponer de la información pertinente que le hubiera permitido comprender las consecuencias jurídicas que se derivaban para él de tal cláusula; la segunda es abusiva per se.

Como bien se alcanza — cierro ya el paréntesis-, en esto el criterio mayoritario de la Sala Primera se ve expresamente desautorizado desde Luxemburgo.

Un consumidor — sentencia el TJUE - no puede comprometerse válidamente a renunciar para el futuro a la tutela judicial y a los derechos que le confiere la Directiva 93/13. Y no puede - justifica, en línea también con el AG- porque en tal caso la renuncia no puede considerarse "informada", habida cuenta de que, en el momento es que se expresa, el consumidor no concibe ni atribuye importancia a la posibilidad de que en el futuro surjan conflictos con el profesional y necesite de la protección que le brinda la Directiva.

\section{CONCLUSIÓN}

Aunque en buena medida ya la he ido expresando, dedico estas líneas finales a plasmar negro sobre blanco la opinión que me merece esta Sentencia.

Del lado de los méritos, entiendo que los principales son dos: aclarar que el sistema europeo de protección al consumidor no tiene carácter obligatorio para este último y, al tiempo, impedir que este sistema resulte ineficaz a través de la renuncia previa de acciones. Los mismos méritos, en suma, que en nuestro ordenamiento patrio se derivan del principio de autonomía de la voluntad y de la regulación sectorial de la renuncia (arts. 10, 82 y 86 TRLGDCU).

En el reverso de la moneda —el de los deméritos-, tengo para mí que estos también son dos: el de su imprecisión en torno a los criterios a tener en cuenta en aras a considerar que una cláusula de renuncia de acciones puede ser abusiva; y el de su absoluto silencio sobre el art. 47 de la Carta de los Derechos Fundamentales de la Unión Europea; algo incomprensible - piensotratándose de la renuncia al ejercicio de acciones.

Hasta aquí, como digo, mi opinión, con la que naturalmente se puede comulgar o disentir.

En la esfera de lo indiscutible queda el carácter excepcional de esta Sentencia. Y por partida doble. Al fin y al cabo, es la primera vez que el TJUE

dicho Anexo no deben necesariamente considerarse abusivas y que, por el contrario, una cláusula que no figura en él puede ser tenida por tal (Comisión c. Suecia, 2002). 
otorga un tratamiento diferenciado a los contenidos de una misma cláusula contractual; y la segunda que, en vez de encomendar la apreciación de la abusividad de una cláusula a los tribunales nacionales, se decanta por declararla él mismo abusiva ${ }^{17}$.

\section{FUENTES CITADAS}

\section{A. Bibliografía}

Achón Bruñen, M. J. (2019). Casuística del desistimiento y la renuncia: soluciones a problemas prácticos. Práctica de Tribunales, n. ${ }^{\circ} 136$.

Aguilera Morales, M. (2019). La cláusula de renuncia al ejercicio de acciones: entre la autonomía de la voluntad y los derechos del consumidor. En F. Jiménez Conde y R. Bellido Penadés (Dirs.), Justicia: ¿Garantías versus eficiencia? Tirant lo blanch (pp. 61-88).

- (2020). ¿Es válida la cláusula de renuncia de acciones predispuesta frente al consumidor? En M. Aguilera Morales (Dir.), Tribunal de Justicia de la Unión Europea, Justicia civil y derechos fundamentales. Thomson Reuters, Aranzadi (pp. 19-45).

Moreno García, L. (2019). Las cláusulas abusivas y su tratamiento procesal. Tirant lo blanch.

Muñoz García, C. (2018a). Comentario a la STS de 11 de abril de 2018. ¿Novación o contrato de transacción? Solución a la posible falta de transparencia en la cláusula suelo, en M. Yzquierdo Tolsada (Coord.), Comentarios a las Sentencias de unificación de doctrina: civil y mercantil, vol. 10 (pp. 73-88).

- (2018b). Falta de transparencia, posible ineficacia y acuerdo transaccional válido. Revista de Derecho Bancario y Bursátil, núm. 152 (pp. 165-200).

Pazos Castro, R. (2017). La retroactividad de la nulidad de la cláusula suelo según el TJUE: luces y sombras". La Ley Unión Europea, n. ${ }^{\circ} 4$.

\section{B. Legislación y jurisprudencia}

Auto TJUE. (2019). Bankia, C-92-16, ECLI: EU:C:2019:560.

Auto TJUE. (2019). Globalcaja, C-617/18. ECLI:EU:C:2019:70.

Carta de los Derechos Fundamentales de la Unión Europea. DOUE C 364 (18 de dic. de 2000).

Conclusiones AG (Henrik Saugmandsgaardøe), Ibercaja Banco, C-452/18. ECLI:EU: C:2020:61.

Directiva 93/13/CEE, del Consejo, de 5 de abril de 1993, sobre las cláusulas abusivas en los contratos celebrados con consumidores. DOCE núm. 95 (21 de abr. de 1993).

Directiva 2011/83/ UE del Parlamento Europeo y del Consejo de 25 de octubre de 2011 sobre los derechos de los consumidores, por la que se modifican la Directiva 93/13/ CEE del Consejo y la Directiva 1999/44/CE del Parlamento Europeo y del Consejo

17 La primera vez en hacer un pronunciamiento de este tipo fue veinte años atrás, en Océano Grupo Editorial (2000). En este asunto, en efecto, el TJUE declaró abusiva una cláusula atributiva de competencia en favor del tribunal en cuyo territorio se encontraba el domicilio de profesional, al considerar que esta cláusula le favorecía exclusivamente y no comportaba contrapartida alguna para el consumidor. 
y se derogan la Directiva 85/577/CEE del Consejo y la Directiva 97/7/CE del Parlamento Europeo y del Consejo- DOUE L 304 (22 de nov. de 2011)

Directiva 2013/11/CEE sobre resolución alternativa de litigios en materia de consumo. DOUE L 165 (18 de jun. de 2013).

Directiva 2014/17/UE del Parlamento Europeo y del Consejo, de 4 de febrero de 2014, sobre los contratos de crédito celebrados con los consumidores para bienes inmuebles de uso residencial y por la que se modifican las Directivas 2008/48/CE y 2013/36/UE y el Reglamento (UE) n. ${ }^{\circ}$ 1093/2010. DOUE L 60 (28 de feb. de 2014).

Ley $5 / 2019$, de 15 de marzo, reguladora de los contratos de crédito inmobiliario. ES. BOE núm. 65 (6 de mar. de 2019).

Real Decreto Legislativo 1/2007, de 16 de noviembre, por el que se aprueba el texto refundido de la Ley General para la Defensa de los Consumidores y Usuarios y otras leyes complementarias. ES. BOE n. 287 (30 de nov. de 2007).

Real Decreto Ley 1/2017, de 20 de enero, de medidas urgentes de protección de consumidores en materia de cláusulas suelo. ES. BOE n. ${ }^{\circ} 18$ (21 de ene. de 2017).

Sentencia TJUE. (2000). Océano Grupo Editorial, C-240/98 a 244/98. ECLI: EU:C:2000:346.

Sentencia TJUE. (2009). Pannon GSM, C-243/08. ECLI: EU:C:2009:350.

Sentencia TJUE. (2013). Banif Pluss, C-472/11, ECLI: EU:C:2013:88.

Sentencia TS 241/2013 (9 de mayo). ECLI:ES:TS:2013:1916.

Sentencia TS 63/2016 (12 de feb.) ECLI: ES:TS:2016:503.

Sentencia TJUE. (2016). Sales Sinués y Drame Bra, C-381/14 y C-385/14. ECLI: EU:C:2016:252.

Sentencia TJUE. (2016). Verein für Konsumenteninformation. C-191/15, ECLI: EU:C:2016:612.

Sentencia TJUE. (2016). Gutiérrez Naranjo y otros, C-145/15, C-307/15 y C-308/15, ECLI: EU:C:2016:980.

Sentencia TJUE. (2002). Comisión c. Suecia, C-478/99. ECLI: EU:C:2002:281.

Sentencia TS 558/2017 (16 de oct.). ECLI:ES:TS:2017:3721.

Sentencia TS 205/2018 (11 de abr.). ECLI:ES:TS:2018:1238.

Sentencia TJUE. (2018). Smith, C-122/17. ECLI:EU:C:2018:631.

Sentencia TS 137/2019 (6 de mar.). ECLI: ES:TS: 2019:677.

Sentencia TJUE. (2019). Abanca Corporación Bancaria y Bankia, C-70/17 y C-179/17. ECLI: EU:C:2019:250.

Sentencia TJUE. (2019). Dziubak, C-260/18. ECLI: EU:C:2019:819.

Sentencia TJUE. (2020). Gómez del Moral Guasch/Bankia, C-125/18, ECLI:EU:C:2020:138.

Sentencia TJUE. (2020). Ibercaja Banco, C-452/18. ECLI:EU:C:2020:536.

Sentencia TJUE. (2020). Caixabank y BBVA, C-224/19 y C-259/19. ECLI:EU:C:2020:578. 
